\title{
Pandemics after 2000 and Their Economic Effects
}

\author{
Dilek Tok \\ a Turkey, dilekpasahan.tok@gmail.com, https://orcid.org/0000-0002-7432-5428
}

\section{ARTICLE INFO}

Research Article

2022, Vol. 4(1), 33-45

e-ISSN 2667-5927

Article History:

Received: 01.09.2021

Revised: 22.11.2021

Accepted: 26.11.2021

Available Online: 30.01.2022

JEL Code: F60, I10, EOO

Keywords: epidemic, pandemic, SARS, H1N1, swine flu, MERS, ebola, covid-19, coronavirus, economic effects

Anahtar Kelimeler: salgın, pandemi, SARS, H1N1, domuz gribi, MERS, ebola, covid-19, koronavirüs, ekonomik etkiler
Pandemics after 2000 and Their Economic Effects

Abstract

When we look at the world history, we see that many pandemics have emerged from the past to the present and that these pandemics have ceased to be a public health problem and have led to economic crisis. While pandemics are transmitted fom person to person, they are also economically transmitted from country to country. After 2000, five major pandemics emerged, namely SARS, swine flu, MERS, Ebola and Covid-19, and these pandemics caused economic losses. It is seen that the higher the infectiousness, mortality and duration of the pandemic, the higher the economic loss. Respectively, SARS \$33 billion, swine flu $\$ 45-55$ billion, MERS $\$ 10$ billion, Ebola $\$ 53$ billion and Covid-19 have caused economic losses worth $\$ 9$ trillion so far. When we look at the economic losses, it is seen that the value of economic losses is less because the infectiousness and mortality of SARS and MERS are less than other pandemics. On the other hand, the Covid-19 pandemic presents a more serious economic picture as a result of factors such as the number of cases, death rate, the emergence and rapid spread of new mutations and the fact that it still continues. All the aforementioned pandemics have had significant consequences on investment, production, consumption, employment, inflation, exchange rate, foreign trade and markets, as well as sectoral income losses.

In this study, it is aimed to evaluate the effects of recent pandemics on the world economy, based on the fact that pandemics cause economic crises. Thus, the economic losses caused by the major pandemics after 2000 can be seen numerically and it will be possible to determine which areas of the economy are more affected.

2000 Sonrası Salgınlar ve Ekonomik Etkileri

$\ddot{O} z$

Dünya tarihine baktığımız zaman geçmişten günümüze çok sayıda salgının ortaya çıktığını ve bu salgınların halk sağlığı problemi olmanın ötesine geçerek ekonomik krizlere yol açtı̆ıını görmekteyiz. Salgınlar kişiden kişiye bulaşırken ülkeden ülkeye de ekonomik bulaşıcılık göstermektedir. 2000 sonrasında sırayla SARS, Domuz Gribi, MERS, Ebola ve Covid-19 olmak üzere beş büyük salgın ortaya çıkmış ve bu salgınlar ekonomik kayıplara yol açmıştır. Salgının bulaşıcılığı, öldürücülügüü ve etki süresi ne kadar yüksekse ekonomik kaybın da o denli yüksek olduğu görülmektedir. Sırasıyla SARS 33 milyar \$, domuz gribi 4555 milyar \$, MERS 10 milyar \$, Ebola 53 milyar \$ ve Covid-19 şimdiye kadar 9 trilyon \$ değerinde ekonomik kayba yol açmıştır. Ekonomik kayıplara baktığımız zaman SARS ve MERS'nin bulaşıcıliğının ve öldürücülüğünün diğer salgınlardan daha az olması nedeniyle ekonomik kayıp değerinin daha az olduğu görülmektedir. Diğer taraftan vaka sayısı, ölüm oranı, yeni mutasyonların ortaya çıkısıı, hızlı yayılımı ve hala devam ediyor olması gibi faktörler Covid-19 salgınının ekonomik olarak daha ağır bir tablo vermesini sağlamaktadır. Bahsi geçen tüm salgınlar sektörel gelir kayıplarının yanı sıra yatırım, üretim, tüketim, istihdam, enflasyon, döviz kuru, dış ticaret ve piyasalar üzerinde önemli sonuçlar doğurmuştur.

Çalışmada ekonomik krizlere neden olduğu gerçeğinden hareketle özellikle yakın tarihte gerçekleşen salgınların dünya ekonomisi üzerindeki etkilerinin değerlendirilmesi amaçlanmıştır. Böylece 2000 sonrasında yaşanan büyük salgınların yarattığı ekonomik tahribat sayısal olarak görülebilecek ve ekonominin hangi alanlarını daha fazla etkilediği belirlenebilecektir.

To cite this document: Tok, D. (2022). Pandemics after 2000 and Their Economic Effects.BILTURK, The Journal of Economics and Related Studies, 4(1), 33-45. doi: 10.47103/bilturk.989451. 
Tok, D. (2022). Pandemics after 2000 and Their Economic Effects.BILTURK, The Journal of Economics and Related Studies, 4(1), 33-45. doi: $10.47103 /$ bilturk.989451.

\section{Giriş}

21.yy. öncesinde dünya en ölümcül olan ve yaklaşık olarak 200 milyon insanın ölümü ile sonuçlanan Kara Ölüm (Hıyarcıkıı Veba) olarak ifade edilen ve bunun gibi çok sayıda salgınla mücadele etmiştir (Britannica, 2021; McEvedy, 1988). 21. yy.'da ise gerek tedavi yöntemleri gerekse yetişmiş insan gücü ve teknoloji ile birlikte yeni bir salgın durumunda yeni virüsün genomunu çözüp etkin aşı bulunması daha hızlı gerçekleşmektedir. Böylece ölüm oranları düşmektedir. Her ne kadar teknolojinin, tıbbın, ilaç endüstrisinin gelişmesi salgınlar neticesinde yaşanan can kaybını azaltsa da salgınların ekonomide yarattığı tahribatın önüne geçememektedir.

Dünya tarihinde yaşanan ve kitlesel ölümlere yol açan salgınlar neticesinde herhangi bir salgın vuku bulduğunda ölüm korkusu ve geleceğe yönelik belirsizlikler salgının halk sağlığı problemi olması ötesine geçmektedir. Geleceğe yönelik belirsizliklerin artması ekonomik durgunluk sürecini hızlandırmaktadır.

Diğer yandan salgın tedbirleri kapsamında uygulanan karantina tedbirleri hem arz hem talep yönünde daralmaları meydana getirmektedir. Dolayısıyla salgın ekonominin tüm alanlarında hissedilir düzeyde kriz ortaya çıkarmaktadır. Salgının bulaşıcılığı, ölüm sayısı, etki süresi gibi faktörler ekonomik krizin boyutunu etkileyen faktörlerdir. Bir salgının bulaşıcılığı ne kadar yüksekse ekonomik krizin boyutu da o denli ağır olmaktadır.

\section{Şekil 1: 2000 Sonrası Salgınların Bulaşma Hızı}

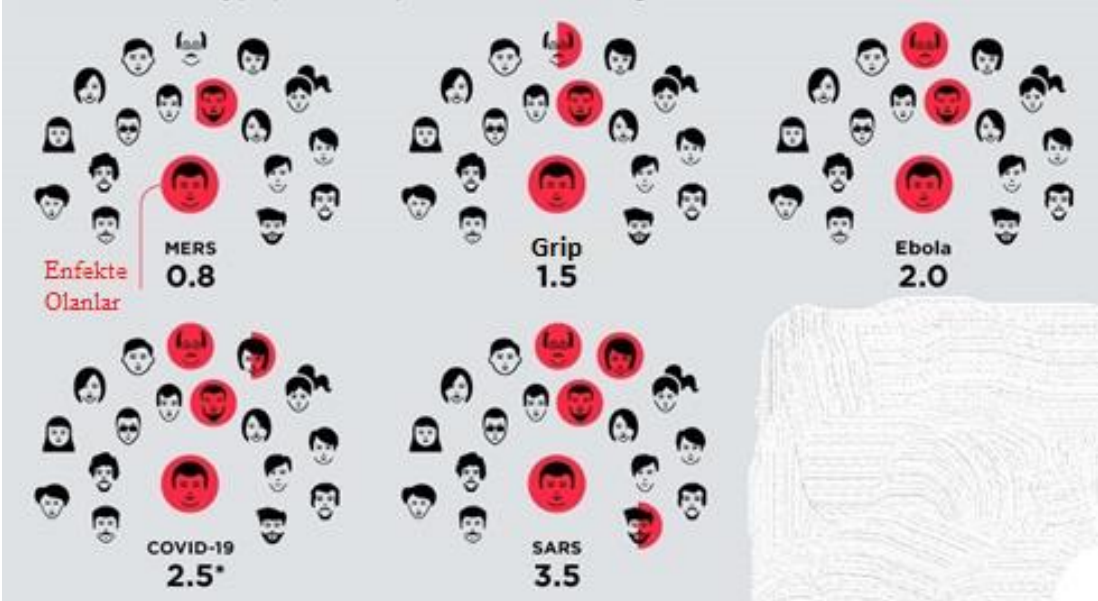

Kaynak: Le Pan, 2020.

Şekil 2000 sonrasında yaşanan salgınlarda salgına yakalanmış bir kişinin ortalama kaç kişiye salgını bulaştırabileceğini göstermektedir. Şekle göre SARS'nin bulaşıcılığı en yüksek iken Covid-19'un bulaşıcılığı SARS'den sonra gelmektedir. SARS'ye yakalanan kişi ortalama 3,5 kişiyi enfekte edebilirken Covid-19'a yakalanan bir kişi ortalama 2,5 kişiyi enfekte edebilmektedir. SARS'nin bulaş riski daha yüksek olmasına karşın ölüm oranı daha düşüktür buna karşın Covid-19' un ölüm oranı SARS 
Tok, D. (2022). Pandemics after 2000 and Their Economic Effects.BILTURK, The Journal of Economics and Related Studies, 4(1), 33-45. doi: $10.47103 /$ bilturk.989451.

ile kıyaslanamayacak boyuttadır. Diğer taraftan Covid-19 salgınının devam ediyor olması ve yeni mutasyonların ortaya çıkma beklentisi yaşanabilecek ekonomik, sosyal, psikolojik sorunlar konusunda kamuoyunda endişe uyandırmaktadır.

2000 sonrası yaşanan büyük salgınları sırayla SARS, domuz gribi, MERS, Ebola ve Covid-19 olarak sıralayabiliriz. Bu salgınların tarihleri, salgın etkeni ve yaşanan kayıplar aşağıda tablo halinde verilmiştir.

Tablo 1: 2000 Sonrası Yaşanan Büyük Salgınlar

\begin{tabular}{llll}
\hline \hline Tarih & Salgının Adı & $\begin{array}{l}\text { Salgın } \\
\text { Etkeni }\end{array}$ & Ölüm Sayısı \\
\hline \hline $2002-2003$ & $\begin{array}{l}\text { SARS (Severe Acute Respiratory Syndrome-Şiddetli } \\
\text { Akut Solunum Yolu Sendromu) }\end{array}$ & $\begin{array}{l}\text { SARS- } \\
\text { CoV }\end{array}$ \\
& $\begin{array}{l}\text { Swine Flu (Domuz Gribi) } \\
2009-2010\end{array}$ & H1N1 & $151,700-575,400$ \\
$2012-2014$ & MERS (Middle East Respiratory Syndrom-Orta Doğu & MERS- & 858 \\
& Solunum Yolu Sendromu) & CoV & \\
$2014-2016$ & Ebola & Ebola & 11,325 \\
& & Virüsü & \\
2019 'dan günümüze & Covid-19 & SARS- & $4,517,893$ \\
& & CoV-2 & $(30.08 .2021)$ \\
\hline \hline
\end{tabular}

Kaynak: CDC, 2003; Kaner ve Schaack, 2016; CDC, 2019; Ay, 2020; CEBM, 2020; Worldometers, 2021 çalışmalarından yararlanılarak yazar tarafından hazırlanmışır.

2000 sonrası yaşanan ilk salgının SARS olduğu görülmektedir. SARS salgını 20022003 döneminde etkili olmuş, Çin'de ortaya çıkmış ve 774 kişinin ölümüyle sonuçlanmıştır (CDC, 2003). Ardından 2009-2010 döneminde Kaliforniya'da domuz gribi ortaya çıkmış ve tam sayı bilinmemekle birlikte salgına bağlı ölüm sayısının $151,700-575,400$ arasında olduğu tahmin edilmektedir (CDC, 2019). MERS salgını Suudi Arabistan'da ortaya çıkmış, 2012-2014 döneminde etkili olmuş ve 858 kişinin ölümüne yol açmıştır (Ay, 2020). Ebola ise Batı Afrika'da ortaya çıkmış, 2014-2016 döneminde varlığını sürdürmüş ve bu salgında 11,325 kişinin öldüğü rapor edilmiştir (Kaner ve Schaack, 2016). 2019'da başlayıp günümüze kadar devam eden Covid-19 salgını SARS salgını gibi Çin'de ortaya çıkmış, 28 Ağustos itibariyle 4 milyon 499,271 kişinin ölümüne yol açmıştır (CEBM, 2020). Salgının etkenine baktığımızda SARS, MERS ve Covid-19' un korona virüs kaynaklı olduğu görülmektedir. Diğer salgınlarla karşılaştırıldığında Covid-19 salgınında gerçekleşen ölüm sayısının daha fazla olduğu görülmektedir. Bu salgının hızlı yayılım göstermesi ve yeni varyantlarının ortaya çıkışı Covid-19 salgınının diğer salgınlara göre ekonomide yarattığı tahribatı artırmaktadır.

Çalışma kapsamında 2000 sonrasında yaşanan SARS (Severe Acute Respiratory Syndrome-Şiddetli Akut Solunum Yolu Sendromu), Domuz Gribi (Swine Flu), MERS (Middle East Respiratory Syndrome- Orta Doğu Solunum Yolu Sendromu), Ebola ve Covid-19 salgınları incelenerek bu salgınların ekonomik etkileri değerlendirilmektedir. 
Tok, D. (2022). Pandemics after 2000 and Their Economic Effects.BILTURK, The Journal of Economics and Related Studies, 4(1), 33-45. doi: $10.47103 /$ bilturk.989451.

\section{SARS Salgını (2002-2003)}

21. yy.'ın ilk pandemisi olan SARS 2002 yılında Çin'den başlayarak Asya'ya yayıımış ve geçmişteki salgınlar gibi yüksek ölüm beklentisi insanlarda panik yaratmıştır. Sağlık otoriteleri salgınla mücadele ederken ekonomide gerekli olmayan seyahatler yasaklanmış, havayolu şirketleri iflas eşiğine gelmiş, ulusal ekonomiler gittikçe kötüye gitmiş ve uluslararası finansal piyasaların çöküşüne yönelik endişe hâkim olmuştur (Scott ve Duncan, 2004: 1-2). Buna karşın SARS salgını Asya dışında Avrupa, Kuzey ve Güney Amerika ülkelerini kapsayan toplam 27 ülkede 8098 vaka ve 774 ölüm ile sonuçlanmıştır (CDC, 2003).

SARS salgınında seyahat kısıtlamalarının getirilmesi havayolu şirketlerinde gelir kaybına yol açmıştır. Asia-Pacific şirketi 6 Milyar \$ gelir kaybederken Kuzey Amerika havayolu şirketi 1 Milyar \$ kaybetmiştir. Singapur Havayolları kapasitesini \%71 oranında azaltmış ve 6600 kişilik uçuş ekibini ücretsiz izne çıkarmıştır. Bu durum Singapur'un turizm gelirlerini \%70 oranında düşürerek GSYH'sinde 400 milyon \$'lık değer kaybı oluşturmuştur. Hong Kong, Singapur ve Çin'de geniş satış ağına sahip kozmetik şirketi Estee Lauder da salgından olumsuz etkilenmiştir. Turizmdeki kısıtlamalar neticesinde petrol talebinin azalması petrol üreten ve ihraç eden ülkelerin de petrol gelirlerinin azalmasına neden olmuştur. Seyahat kısıtlamaları nedeniyle kaybeden sektör sadece havayolu olmamış, turizm sektörü de olumsuz etkilenmiştir. Las Vegas'taki Ceaser's Palace ve diğer kumar ve otel komplekslerinin sahibi Park Palace Entertainment'ın net geliri 2003 yılının ikinci çeyreğinde bir önceki yıla göre \%50'den fazla azalmıştır (Begley, 2013).

Tablo 2: SARS Nedeniyle 2003 Yılında GSYH'deki Değiş̧im

\begin{tabular}{lllll}
\hline \hline Ülke & Toplam Etki & Talep Kayması & Maliyet Artışı & Ülke Riski \\
\hline \hline ABD & $-0,07$ & $-0,01$ & $-0,06$ & 0,00 \\
Japonya & $-0,07$ & $-0,01$ & $-0,06$ & 0,00 \\
Avustralya & $-0,07$ & 0,00 & $-0,06$ & 0,00 \\
Yeni Zelanda & $-0,08$ & 0,01 & $-0,08$ & 0,00 \\
Endonezya & $-0,08$ & 0,01 & $-0,09$ & 0,00 \\
Malezya & $-0,15$ & 0,01 & $-0,16$ & 0,00 \\
Filipinler & $-0,10$ & 0,04 & $-0,14$ & 0,00 \\
Singapur & $-0,47$ & $-0,02$ & $-0,45$ & 0,00 \\
Tayland & $-0,15$ & 0,00 & $-0,15$ & 0,00 \\
Çin & $-1,05$ & $-0,37$ & $-0,34$ & $-0,33$ \\
Hindistan & $-0,04$ & 0,00 & $-0,04$ & 0,00 \\
Tayvan & $-0,49$ & $-0,07$ & $-0,41$ & $-0,01$ \\
Kore & $-0,10$ & $-0,02$ & $-0,08$ & 0,00 \\
Hong Kong & $-2,63$ & $-0,06$ & $-2,37$ & $-0,20$ \\
OECD & $-0,05$ & 0,00 & $-0,05$ & 0,00 \\
Doğu Avrupa ve Rusya & $-0,06$ & $-0,01$ & $-0,05$ & 0,00 \\
OPEC & $-0,07$ & $-0,01$ & $-0,05$ & 0,00 \\
\hline \hline
\end{tabular}

Kaynak: Lee ve McKibbin, 2004.

SARS salgını dünya GSYH'sinde 33 milyar \$’ın üzerinde kayba yol açmıştır. SARS, Çin ekonomisini önemli ölçüde etkilemiş ve en fazla daralma turizm sektöründe gözlenmiştir. Çin'in turizm geliri yurtdışından 10,8 milyar \$, yurtiçinden 6 milyar \$ kayıp vermiştir. Toplamda turizm sektörü 16,8 milyar $\$$ değerinde zarar görmüştür. 
Ekonomide çarpan mekanizması ile tüm Çin ekonomisinde 25,3 milyar \$’lık kayıp gerçekleşmiştir (Hai vd., 2004:57).

Tablo 2'ye bakıldığında SARS'nin etkisinin Hong Kong başta olmak üzere sırayla Çin, Tayvan ve Singapur'un GSYH'lerinde yoğunlaştığı görülmektedir. Hong Kong'un GSYH'sindeki kayıp \%2,63 iken Çin'in \%1,05, Tayvan'ın \%0,49 ve Singapur'un $\% 0,47$ 'dir. SARS salgını hizmet sektörü başta olmak üzere birçok sektörü etkilemiştir. Hong Kong'da hizmet sektörünün payının yüksek olması salgın neticesinde GSYH'nin daha fazla azalması ile sonuçlanmıştır.

\section{Domuz Gribi (2009-2010)}

H1N1 virüsü ile bulaşan Domuz gribi (Swine Flu) ilk olarak 2009 yılında Kaliforniya'da görülmüştür. Daha sonra Meksika, İspanya, İngiltere, Amerika ve Kanada'ya yayılmıştır. Ölüm sayısının 151,700-575,400 kişi arasında olduğu belirtilmektedir (Baldwin ve Mauro, 2020:6). Diğer salgınlarda olduğu gibi domuz gribi salgınında da her ülke, her sektör ve bir sektör içinde farklı iş kolları da aynı düzeyde etkilenmemiştir. Salgından bir ülke, sektör veya iş kolu kayıp yaşarken diğeri kar sağlayabilmektedir. Bu perspektifte domuz gribi salgınında bazı ilaç şirketlerinin karlarını artırdığını söylemek yanlış olmayacaktır. Nitekim SanofiAventis şirketi gelirini \%11 oranında artırmıştır (Begley, 2013). Dünyada H1N1 virüsü kaynaklı domuz gribi salgınında 45-55 milyar \$ civarında ekonomik kayıp yaşandığı düşünülmektedir (GPMB, 2019:13-14).

\section{MERS (2012-2014)}

MERS (Middle East Respiratory Syndrome) Orta Doğu Solunum Sendromu olarak literatürde geçmektedir. SARS gibi MERS'de de korona virüs ailesinden salgın etkeni bulunmaktadır. İlk olarak 2012 yılında Suudi Arabistan'da ortaya çıkmıştır. Daha sonra Cezayir, Avusturya, Malezya, Hollanda, Umman, Filipinler, Katar, Kore, Tayland, Tunus, Türkiye, Birleşik Arap Emirlikleri, Ingiltere, Amerika ve Yemen dahil toplam 27 ülkede 2494 vaka ve toplam 858 kişinin ölümü ile sonuçlanmıştır (Ay, 2020: 159-161). Dünyada MERS salgını 10 milyar \$ civarında ekonomik kayba yol açmıştır (GPMB, 2019:13-14).

\section{Ebola Salgını (2014-2016)}

Ebola 2014 yılında Batı Afrika'da ortaya çıkmış ve hızla Gine, Liberya ve Sierra Leone'ye yayılmıştır. Daha sonra İspanya ve Amerika'da da görülmüştür. Salgında toplam 28,652 vaka ve 11,325 ölüm gerçekleşmiştir (Kaner ve Schaack, 2016: 3-4). Dünyada Ebola salgınının 53 milyar \$’lık ekonomik kayba yol açtığı bilinmektedir. Ebola salgınında etkilenen ülkelerde turizm \%50 oranında azalmış, işsiz sayısı \%51 artmıştır (GPMB, 2019:13-14). 
Tok, D. (2022). Pandemics after 2000 and Their Economic Effects.BILTURK, The Journal of Economics and Related Studies, 4(1), 33-45. doi: $10.47103 /$ bilturk.989451.

Ebola salgınından en çok etkilenen ülkeler olan Gine, Sierra Leone ve Liberya'ya salgının maliyetinin 2,8 milyar \$ olduğu tahmin edilmektedir. Bunun 600 milyon \$'। Gine, 300 milyon \$'ı Liberya ve 1,9 milyar \$'ının Sierra Leone'ye ait olduğu düşünülmektedir. Özellikle Sierra Leone' de en çok madencilik sektörü etkilenmiştir. Diğer yandan boksit, demir, altın gibi ürün fiyatlarının düşmesi (\%30-\%60 arasında) yanında yatırım, üretim ve tüketimde görülen düşüşler ekonomileri salgının öldürücü etkisinden daha fazla etkilemiştir. Kişi başı ölüm 10.000 kişide 5 kişi iken kişi başı GSYH ortalama 125 \$ azalmıştır (World Bank, 2016).

Grafik 1: Eboladan En Çok Etkilenen 3 Ülkeye Ait GSYH'deki \% Değişim
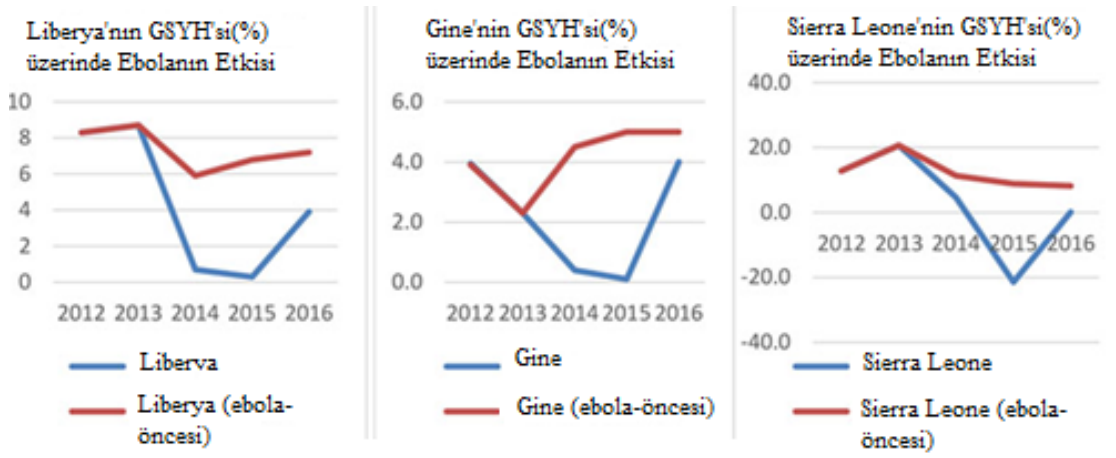

Kaynak: World Bank, 2016.

Grafiğe bakacak olursak Liberya'da reel GSYH büyümesi 2013 yılında \%8,7'den 2014 yılında \%0,7’ye düşmüştür. Liberya'nın 2015 yılından itibaren GSYH'sini artırdığı ancak ebola öncesi ekonomik görünümünü yakalamadığı görülmektedir. Gine'de ebola öncesi reel GSYH büyümesi \%4 düzeyindeyken ebola salgınında \%0,1'leri görmüştür. Gine, 2015'ten sonra hızlı bir toparlanmaya girmiştir. 2013 yılında Sierra Leone'nin reel GSYH büyümesi \%20,7 iken ebola salgınında \%-21,5'e kadar düşmüştür. En çok etkinin Sierra Leone'de ortaya çıktığı bu grafikten de görülmektedir.

\section{COVID-19 Salgını (2019-günümüze)}

Covid-19 salgını ilk olarak Aralık 2019'da Çin'in Hubei eyaletinin Wuhan şehrinde ortaya çıkmıştır. Covid-19 korona virüs ailesinden yeni tip korona virüs olarak ifade edilen, dünya çapında hızı yayılan, özellikle yaşlı, kronik hastalığı veya ölümcül hastalığı olanlar ile bağışıklık sistemi savunmasız olanlar üzerinde ölümcül sonuçları olan bir salgındır (McKibbin ve Fernando, 2020; Abodunrın vd., 2020). Salgın uzun dönem sağlık sorunlarının yanı sıra eğitim, seyahat, ticaret gibi birçok sektörde olumsuz sonuçlar doğurmaktadır. Günümüzde aşılama çalışmaları hız kazanmasına rağmen değişik mutasyonlarla yayılımı ve öldürücülüğü devam etmektedir. Çalışmanın yazıldığı zamana kadar sırasıyla Danimarka, İngiltere, İrlanda ve Güney Afrika mutasyonları gerçekleşmiştir (WHO, 2020). 30 Ağustos 2021 itibariyle dünya çapında 217,350,576 vaka ve 4,517,893 ölüm rapor edilmiştir (Worldometers, 2021). 
Tok, D. (2022). Pandemics after 2000 and Their Economic Effects.BILTURK, The Journal of Economics and Related Studies, 4(1), 33-45. doi: $10.47103 /$ bilturk.989451

Covid-19 salgınında 30 Ağustos 2021 itibariyle vaka sayısı ve ölüm sıralamasında ABD birinci sırada yer almaktadır. Vaka sayısı en fazla olan 10 ülke sırasıyla ABD $(39,665,515)$, Hindistan $(32,737,939)$, Brezilya $(20,741,815)$, Rusya $(6,901,152)$, Fransa $(6,742,488)$, Ingiltere $(6,731,423)$, Türkiye $(6,346,881)$, Arjantin $(5,173,531)$, İran $(4,960,744)$ ve Kolombiya'dır $(4,905,258)$. Ölüm sayısı en fazla olan 10 ülke ise sırasıyla ABD $(654,689)$, Brezilya $(579,330)$, Hindistan $(438,387)$, Meksika $(258,165)$, Peru $(198,167)$, Rusya $(182,429)$, Ingiltere $(132,437)$, Endonezya $(132,491)$, İtalya $(129,093)$ ve Kolombiya'dır $(124,811)$. Çin 94,842 vaka sayısı ile 107. sıradadır. Çin'de Covid-19 kaynaklı toplam ölüm sayısı ise 4,636'dır (Worldometers, 2021). Şimdiye kadar Covid-19 salgınının dünya ekonomisine 9 trilyon \$'lık zarar verdiği bilinmektedir (IMF, 2021).

Covid-19 arz ve talep şoklarına yol açmıştır. Arz şoku ilk olarak okulların kapatılması, karantina tedbirleri kapsamında evden online çalışma ve işyerlerinin kapatılması nedeniyle işsizliğin artması şeklinde kendini göstermiştir. Ayrıca ara mal, sermaye ve tüketim malları ile turizm sektöründe talebin daralması sorununu da ortaya çıkarmıştır. Mal ve hizmet piyasalarında talep daraltıcı etki yaratmıştır (Bofinger vd., 2020: 168). Diğer taraftan COViD-19 salgınının geleceği ile ilgili belirsizlikler (yeni mutasyonların ortaya çıkışı, bunların bulaşıcılığı ve ölüm riski konusunda endişelerin varlığı) kişilerin riskten kaçınma eylemlerini artırmaktadır. Yeni mutasyonların görülme ihtimali beraberinde kısıtlayıcı tedbirlerin yeniden alınmasına yol açabileceği beklentisi, piyasa koşullarının öngörülememesi, işsizliğin artışı hane halkı tasarruf eğilimini artırarak harcama eğilimini azaltmaktadır. Dünya ekonomisinin tekrar salgın öncesi haline gelebilmesi piyasada belirsizliğin azalıp güven algısının artması ile pozitif korelasyonludur. Bu anlamda geleceğe yönelik belirsizlik ortadan kalkmadan küresel piyasaların salgın öncesi haline gelmesi zor görünmektedir ve hatta belirsizlik ortadan kalksa dahi harcama, tasarruf eğilimlerinin artması zaman alabilmektedir. Aşağıdaki tablo dünya makroekonomik verilerinden bir kısmını göstermekte ve 2022 tahmini yer almaktadır;

Tablo 3: Dünya Makroekonomik Verileri: 2019-2022*

\begin{tabular}{lllll}
\hline \hline & 2019 & 2020 & 2021 & $2022^{*}$ \\
\hline \hline Reel GSYH Büyümesi & 2,7 & $-3,5 \downarrow$ & $5,8 \uparrow$ & 4,4 \\
Işsizlik Oranı & 5,4 & $7,1 \uparrow$ & $6,6 \downarrow$ & 6,0 \\
Enflasyon & 1,9 & $1,5 \downarrow$ & $2,7 \uparrow$ & 2,4 \\
Cari Denge & $-3,1$ & $-10,8 \uparrow$ & $-10,1 \downarrow$ & $-6,0$ \\
Dünya Ticaret Büyümesi & 1,3 & $-8,5 \downarrow$ & $8,2 \uparrow$ & 5,8 \\
\hline \hline Kaynak: OECD, 2021 & $* 2022$ yllına ait tahmin edilen değerleri göstermektedir.
\end{tabular}

Salgın öncesi ve sonrası ekonomik verileri karşılaştıracak olursak reel GSYH büyümesinin 2020'de negatif olduğu 2021'de pozitife döndüğü ve 2022 tahmininin salgın öncesinin üzerinde gerçekleşeceği öngörülmektedir. İşsizlik oranının 2021'de arttığı ve diğer tüm dönemlerde salgın öncesinden daha yüksek olduğu 
Tok, D. (2022). Pandemics after 2000 and Their Economic Effects.BILTURK, The Journal of Economics and Related Studies, 4(1), 33-45. doi: $10.47103 /$ bilturk.989451.

görülmektedir. Bu durum salgının işsizlik üzerinde kalıcı etkisinin olabileceğini düşündürmektedir. Enflasyon 2021'de bir miktar azalmış ancak diğer dönemlerde yükselmiştir. Cari dengenin ise giderek bozulduğu görülmektedir. Cari dengenin bozulması döviz kurundaki değişim nedeniyle bazı ülkelerin para birimlerinin değerinin düşmesi ile maliyetlerinin artması sonucunda gerçekleşmektedir. Dış ticaret 2021'de azalmış ancak diğer dönemlerde salgın döneminin üzerinde artış göstermiştir. Bu verilerden salgın etkisiyle talep azalmasının ve tasarruf artışının geleceğe dair bir potansiyel oluşturduğunu, olumlu beklentiler halinde talep artışı ve tasarruf çözülmesini sağlayarak ekonomik büyümeye katkı sağlayacağını söylemek mümkündür. Diğer taraftan salgın döneminde birçok sektöre getirilen yasakların ortadan kalkması dış ticarette de etkisini göstererek büyüme hızını artıracaktır. Ancak artan maliyetler neticesinde ortaya çıkan enflasyonist etki ve talebin azalması kaynaklı işsizlik artışının bir süre daha devam edeceği görülmektedir. Uzun vadede ekonominin eski haline dönmesi 2022'den ileri bir tarihte gerçekleşeceği öngörülmektedir.

Grafik 2, 15-74 yaş nüfusun \%'sini temsil etmektedir ve 2022 tahminini göstermektedir. Buna göre salgınının dünyayı etkilediği 2020 yılında istihdam oranı keskin bir şekilde azalmıştır. Tüm dünyada alınan tedbirler ve aşılama çalışmaları kapsamında toparlanmanın olduğu ve 2022'ye yönelik yapılan tahmine göre istihdam oranının pandemi öncesi seviyeye dönmeyeceği görülmektedir.

\section{Grafik 2: Covid-19'un İstihdam Oranına Etkisi}

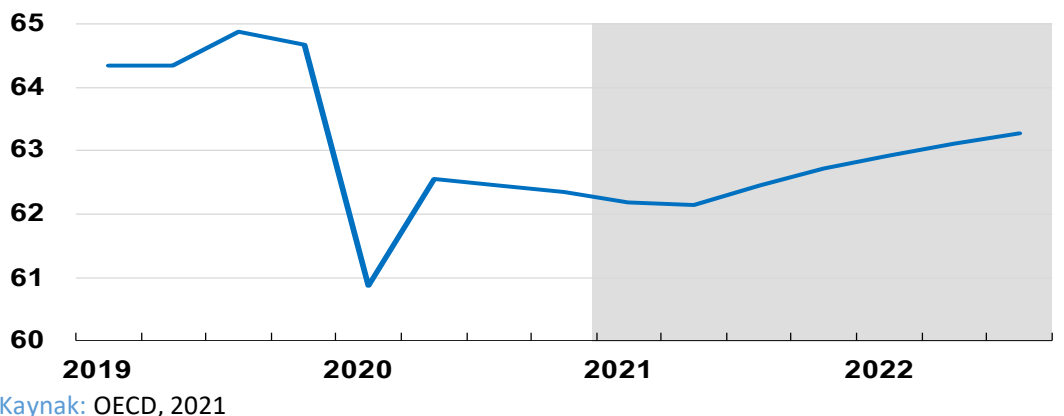

Grafik 3: Covid-19’un Enflasyona Etkisi

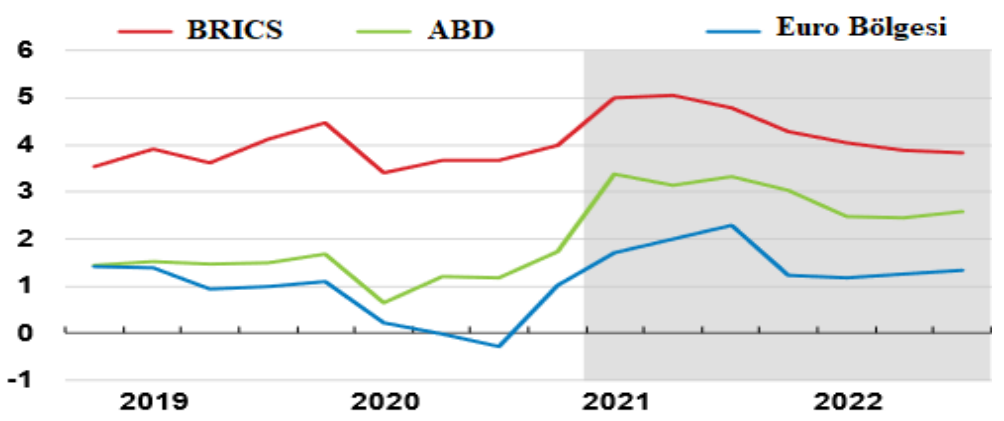

Kaynak: OECD, 2021 
Tok, D. (2022). Pandemics after 2000 and Their Economic Effects.BILTURK, The Journal of Economics and Related Studies, 4(1), 33-45. doi: $10.47103 /$ bilturk.989451.

BRICS ülkeleri, ABD ve Euro bölgesine ait enflasyon grafiğine göre enflasyonun 2020 yılına kadar azaldığı 2021'e gelindiğinde arttığı görülmektedir. Enflasyonun 2020 yılında azalması azalan talep nedeniyle üretim stokunun ortaya çıkması, 2021'de yükselmesi ise genişletici para ve maliye politikaları ile talebin artması aynı zamanda döviz kurundaki değişiklikler sonucu maliyetlerin artması nedeniyledir (T.C. Cumhurbaşkanlığı Strateji ve Bütçe Başkanlığı, 2021; Demiralp, 2021).

\section{Grafik 4: Covid-19'un GSYH'ye Etkisi}

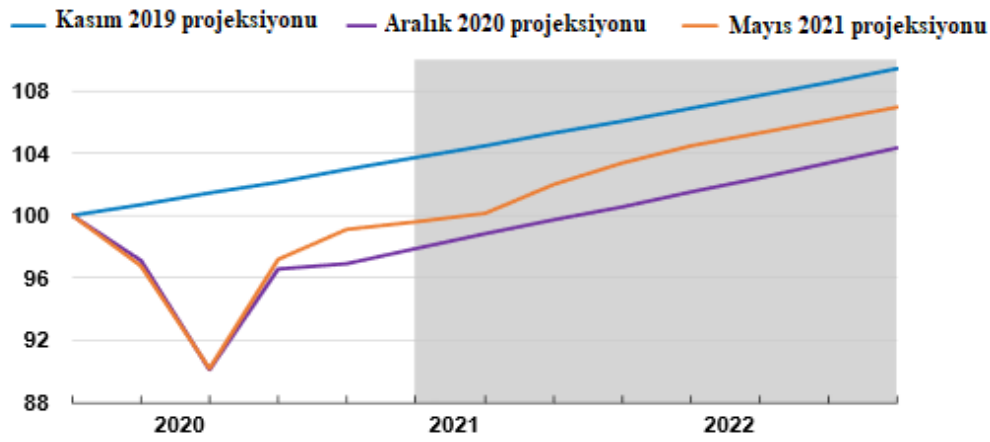

Kaynak: OECD, 2021

Grafikte 2019 yılı baz alınmış ve 2020 yılında GSYH'de ciddi bir azalma yaşanmıştır. Alınan önlemler neticesinde salgının GSYH'de V şeklinde seyir izlediği, 2021'den itibaren toparlanmanın gerçekleştiği görülmektedir. Ancak 2019, 2020 ve 2021'in projeksiyonlarına bakıldığında 2021 yılı ve sonrasında GSYH'nin 2019 yılı seviyesinin gerisinde kaldığı gözlenmektedir. Buna göre dünya ekonomisinin salgın öncesi büyüme seviyesine ulaşabilmesinin biraz daha zaman alacağı öngörülmektedir.

\section{Grafik 5: Covid-19'un Dış Ticarete Etkisi}

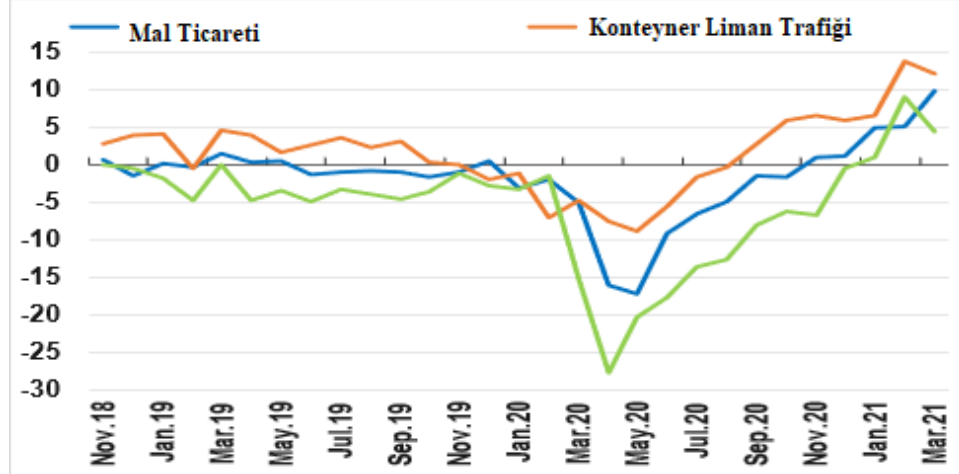

Kaynak: OECD, 2021 
Tok, D. (2022). Pandemics after 2000 and Their Economic Effects.BILTURK, The Journal of Economics and Related Studies, 4(1), 33-45. doi: $10.47103 /$ bilturk.989451.

Salgının dış ticarete etkisi de V şeklinde olmuş buna göre 2020 Ocak'tan Mart'a kadar azalma Mart'tan sonra ise artma eğilimi göstermiştir.

Dünyada aşılama çalışmalarının hızlanması ve yaygınlaşması, geleceğe yönelik belirsizliğin azaltılması, para ve maliye politikalarının talebi artırmaya yönelik düzenlenmesi ile ekonomi üzerindeki negatif etkilerin giderilerek ekonomik toparlanmanın hızlanacağı düşünülmektedir.

Sözü edilen tüm salgınlar için bulaşıcılığı önlemek adına yapılabilecekler şöyle sıralanabilir:

- $\quad$ Sık sık el yıkanmalı, temizlik ve hijyen kurallarına hassasiyet gösterilmelidir.

- Hasta insanlarla temastan kaçınılmalı, kalabalık ve kapalı ortamlarda bulunmaktan kaçınılmalıdır.

- Insanlarla temasta sosyal mesafe korunmalıdır.

- Hastanelerde enfeksiyon önleme konusunda tedbirler geliştirilmelidir.

- Maske takılmalı ve bulunulan ortam sık sık havalandırılmalıdır.

- Salgının olduğu lokasyonlara seyahatler kısıtlanmalı ve hatta yasaklanmalıdır.

- $\quad$ Cezai müeyyidelerle enfekte olmuş kişilerin karantina sürecine uygun davranması sağlanmalıdır.

- $\quad 60$ yaş ve üstü ile kalp, diyabet, hipertansiyon, kanser vb. hastalık geçmişi olan kişiler izole edilmeli ve seyahatleri durdurulmalıdır (WHO, 2020).

- $\quad$ Salgın ve aşılama konusunda kamuoyu yeterince bilgilendirilmelidir.

Bütün salgınlar göstermektedir ki bir ülkede etkin enfeksiyon kontrol mekanizması ile sağlık alanında gelişmiş sağlık altyapısı ve hizmeti (hastane, doktor, yatak sayısı gibi) yoksa ve salgın tedbirlerine uyulmuyorsa o ülkede iyileşme süreci uzamakta, ölüm oranları ve ekonomik tahribat artmaktadır (GPMB, 2019:13).

\section{Sonuç}

Salgınlar tıbbi olarak bulaşıcılık özelliği gösterirken ekonomik olarak da bulaşıcılık gösterirler. Dolayısıyla salgınlar yaşam kaybının yanı sıra ekonomik kayıplara da yol açmaktadır. Salgın dönemlerinde getirilen dışarı çıkma yasakları, okulların eğitime ara vermesi, turizm ve ulaşım kısıtlamaları, kalabalık alanların (alışveriş merkezleri, kişisel bakım salonları, restoranlar, mağazalar, eğlence yerleri, sinema salonları, spor salonları gibi) kapatılması ve bu alanlara girişin uzunca bir süre kısıtlanması insanlarda geleceğe yönelik belirsizlik algısı oluşturmaktadır. Geleceğe yönelik belirsizlikler insanların riskten kaçınma eylemini artırarak ekonomide toplam talebi azaltıcı etki yaratmaktadır. Talebin azalması arz stokunu etkileyerek üretimde azalmaya ve işsizlikte artışa yol açmaktadır. Bununla birlikte döviz kurlarında yaşanan değişimler özellikle ulusal parası değer kaybeden ve ithalata bağımlılığı 
yüksek ülkelerde maliyet artışları neticesinde yüksek enflasyonist etkiler ortaya çıkarmaktadır. Salgınlar neticesinde turizm, havayolu, hizmet sektörleri başta olmak üzere birçok sektörde önemli gelir kayıpları yaşanmıştır. Sektörel gelir kayıpları istihdamın, üretimin, piyasaların da aşağı yönlü hareketine yol açarak GSYH'yi kümülatif olarak çarpan mekanizması ile düşürmüştür. SARS, Domuz Gribi, MERS, Ebola ve Covid-19 gibi 2000 sonrası yaşanan büyük salgınlara baktığımız zaman salgın ne kadar bulaşıcı ve öldürücü ise ekonomik kayıp da o derece yüksek olmuştur. Bu salgınlardan en yüksek vaka ve ölüm sayısı ile diğerleri ile karşılaştırma yapılamayacak kadar fark bulunan Covid-19 salgınının yarattığı ekonomik kaybın da çok yüksek olduğu görülmektedir. 2019 yılından beri salgının yeni mutasyonlarla ve aşılama çalışmalarına rağmen devam ediyor olması belirsizliğe bağlı küresel durgunluğu devam ettirmektedir. Bu yönüyle baktığımız zaman bir salgınının varlığının, bulaşıcılığının ve öldürücülüğünün kontrol altına alınması salgın kaynaklı ekonomik kayıpların minimize edilmesi bakımından önemlidir. 
Tok, D. (2022). Pandemics after 2000 and Their Economic Effects.BILTURK, The Journal of Economics and Related Studies, 4(1),

\section{Kaynaklar}

Abodunrın, O., Oloye, G., ve Adesola, B., (2020). Coronavirus Pandemic and Its Implication on Global Economy. International Journal of Arts, Languages and Business Studies, Vol.4, 13-23.

Ay, A., (2020). Orta Doğu Solunum Sendromu Coronavirüs Salgınları. ESTÜDAM Halk Sağlığı Dergisi, 5, 158-167.

Baldwin, R. ve Mauro, B.W., (2020). Economics in the Time of COVID-19. London: CEPR Press.

Begley, S., (2013). Flu-conomics: The Next Pandemic Could Trigger Global Recession.https://www.reuters.com/article/us-reutersmagazine-davos-flu economy/flu-conomics-the-next-pandemic-could-trigger-global-recessionidUSBRE90KOF820130121, (Erişim Tarihi: 18.08.2021).

Bofinger, P., Dullein, S., Felbermayr, G., Fuest,C., Hüther, M., Südekum, J., ve Mauro, B. W., (2020). Economic Implications of the COVID-19 Crisis for Germany and Economic Policy Measures. London: CEPR Press.

Britannica, (2021). Black Death. https://www.britannica.com/event/Black-Death, (Erişim Tarihi: 20.08.2021).

CDC, (2003). https://www.cdc.gov/mmwr/preview/mmwrhtml/mm5249a2.htm, (Erişim Tarihi: 18.08.2021).

CDC, (2019). 2009 H1N1 Pandemi (H1N1pdm09 virus). https://www.cdc.gov/flu/pandemic-resources/2009-h1n1-pandemic.html, (Erişim Tarihi: 20.08.2021).

CEBM, (2020) https://www.cebm.net/covid-19/covid-19-deaths-compared-withswine-flu/, (Erişim Tarihi: 27.08.2021).

Demiralp, S., (2021). https://www.bbc.com/turkce/haberler-turkiye-56972702, (Erişim Tarihi: 20.08.2021).

GPMB, (2019). A World at Risk: Annual Report on Global Preparedness for Health Emergencies.https://apps.who.int/gpmb/assets/annual_report/GPMB_annualrep ort_2019.pdf, (Erişim Tarihi: 20.08.2021)

Hai, W., Zhao, Z., Wang, J., ve Hou, Z., (2004). The Short-Term Impact of

SARS on the Chinese Economy. Asian Economic Papers, 3(1), 57-61.

IMF, (2021). World Economic Outlook. http://blogs.imf.org, (Erişim Tarihi: 23.08.2021)

Kaner, J., ve Schaack, S., (2016). Understanding Ebola: the 2014 epidemic. Globalization and Health, 12(53), 2-7. 
Tok, D. (2022). Pandemics after 2000 and Their Economic Effects.BILTURK, The Journal of Economics and Related Studies, 4(1),

Le Pan, N., (2020), Visualizing the History of Pandemics.https://www.visualcapitalist.com/history-of-pandemics-deadliest/, (Erişim Tarihi: 15.08.2021).

Lee, J.-W., ve McKibbin, W.J., (2004). Estimating the Global economic Costs of SARS. www.ncbi.nlm.nih.gov/books/NBK92462/, (Erişim Tarihi: 23.08.2021).

McKibbin, W., ve Fernando, R., (2020). The Impact of Covid-19. London: CEPR Press. McEvedy, C., (1988). The Bubonic Plague. Scientific American, 258(2), 118-123.

OECD, (2021). OECD Ekonomik Görünümü 2021. https://www.oecd-ilibrary.org/, (Erişim Tarihi: 19.08.2021).

Scott, S.ve Duncan, C., (2004). Return of the Black Death: The World's Greatest Serial Killer. UK: John Wiley\&Sons.

T.C. Cumhurbaşkanlığı Strateji ve Bütçe Başkanlığı, (2021). Dünya Ekonomisindeki Son Gelişmeler Bülteni. https://www.sbb.gov.tr/wpcontent/uploads/2021/09/Dunya-Ekonomisinde-Son-Gelismeler-2021-Yili-2-

Ceyrek.pdf, (Erişim Tarihi: 20.08.2021).

WHO, (2015). Summary of Probable SARS Cases with Onset of illness from 1 $\begin{array}{lllll}\text { November } & 2002 & \text { to } & 31 & \text { July }\end{array}$ https://www.who.int/publications/m/item/summary-of-probable-sars-caseswith-onset-of-illness-from-1-november-2002-to-31-july-2003, (Erişim Tarihi: 24.08.2021).

WHO, (2020). COVID-19 Global. https://www.who.int/emergencies/diseaseoutbreak-news/item/2020-DON305, (Erişim Tarihi: 16.08.2021).

World Bank, (2016). 2014-2015 West Africa Ebola Crisis: Impact Update. https://www.worldbank.org/en/topic/macroeconomics/publication/2014-2015west-africa-ebola-crisis-impact-update, (Erişim Tarihi: 25.08.2021).

Worldometers, (2021). COVID-19 Coronavirus Pandemic. https://www.worldometers.info/coronavirus/, (Erişim Tarihi: 16.08.2021). 